\title{
A Comparative Situation Analysis of Childhood Asthma Incidence in Selected Hospitals Inside and Outside Dhaka City
}

\author{
Nishat Nasrin ${ }^{1}$, Ferdowsi Akter ${ }^{2}$, Nigar Sultana Tithi ${ }^{1}$, Muhammad Asduzzaman ${ }^{2}$ \\ and AK Azad Chowdhury ${ }^{2}$ \\ ${ }^{1}$ Department of Pharmacy, East West University, A/2 Jahurul Islam Avenue, Jahurul Islam City \\ Aftabnagar, Dhaka-1212. Bangladesh \\ ${ }^{2}$ Department of Clinical Pharmacy and Pharmacology, University of Dhaka, Dhaka-1000, Bangladesh
}

(Received: January 11, 2019; Accepted: January 28, 2020; Published: January 30, 2020)

\begin{abstract}
Asthma is a common chronic and long-term condition accompanied by coughing, wheezing, chest tightness and breathlessness and affects mainly the lungs. This study was aimed to explore the prevailing situation of asthma among the paediatric patients and its management inside and outside Dhaka city. The study was conducted on 420 asthma patients inside $(n=210)$ and outside $(n=210)$ Dhaka. Data were collected using a structured questionnaire from patients or their parents, during the period of January 2015 to June 2015. Most of the patients inside Dhaka reported that their children had frequent asthma attack than outside Dhaka $(\mathrm{p}<0.001)$. Wheezing symptoms were also high in Dhaka $(\mathrm{p}<0.001)$. We observed better management of the disease inside Dhaka as compared with outside $(\mathrm{p}<0.001)$. However, no seasonal variation in terms of exacerbations of symptoms was seen. Moreover, despite greater incidence of childhood asthma in Dhaka city, its management was better here. Mass awareness among parents regarding the incidence and the necessity of continuation of medication as per the advice of physicians are mandatory to reduce the occurrence.
\end{abstract}

Key words: Asthma, pediatric, Dhaka, wheezing, management.

\section{Introduction}

Asthma is a condition in which nasal airways get narrowed and swelled up and produce extra mucus. This can make breathing difficult and trigger coughing, wheezing and shortness of breath (Rodrigo et al., 2004). Globally, it kills around 1000 people every day and affects around 339 million people (The Global Asthma Report 2018). Despite of being a global problem low- and middle-income countries suffer the most severe cases (Cruz et al., 2017). According to Asthma Association of Bangladesh (AAB) report, at present in Bangladesh 70 lakh people are suffering from it. Asthma is a chronic lung disease that affects people of all ages, but it is most prevalent among children. If undiagnosed or undertreated, childhood asthma can possibly restrict individual's activity for life-long creating a substantial burden to individuals and families. Asthma is considered the third leading cause of hospitalization among children under the age of 15 (Al-Otaibi and Al-Ateeq, 2018). Moreover, Dhaka ranks one of the worst in Air Quality Index recently and air pollution can worsen asthma symptoms (Kloepfer and Gern, 2010). Prevalence of asthma varies among different areas of a country (Zaman $e t$ al., 2007). A nationwide prevalence survey in Bangladesh among children and aged populations revealed that the overall prevalence of asthma associated wheezing is higher among children (Hassan et al., 2002).

Correspondence to: Muhammad Asaduzzaman; E-mail: asaduzzaman@du.ac.bd

DOI: https://doi.org/10.3329/bpj.v23i1.45317 
Few studies have been conducted in Bangladesh about prevalence of asthma in children and risk factors associated with it. But there is lack of study comparing overall situation of asthma patients from different places of the country. Therefore, the aim of this study was to explore the scenario of asthma attack among children of Bangladesh and its management and to investigate if there is any variations present between patients in and out of Dhaka city.

\section{Methodology}

This was a prospective, multi-center study and was designed for a comparative analysis on the prevailing situation of asthma management and treatment in paediatric population. This study was conducted in different hospitals/clinics of Dhaka City as well as selected hospitals from several other cities of outside Dhaka. Inside Dhaka, selected hospitals included Dhaka Medical College Hospital, Bangabandhu Sheikh Mujib Medical University Hospital, Dhaka Shishu Hospital, Sir Salimullah Medical College Hospital, Popular Hospital and Diagnostic Center, Shishu Hospital, Crescent Hospital, Al-Beruni Hospital and Khidmah Hospital. Hospitals outside Dhaka City were Chittagong Medical College and Hospital, Chittagong Halishahar General Hospital, Chittagong Maa \& Shishu Hospital, Comilla Medical College and Hospital, Moon Hospital Ltd., Mainamoti Medical College Hospital as well as from Mymensingh Medical College Hospital. The study subjects were the parents and guardians of pediatric patients and few were patients themselves with asthma aged between less than 1 to 16 years. The survey was performed on asthma patients and their parents/guardians inside (n = 210) and outside $(\mathrm{n}=210)$ Dhaka by using convenience sampling.

Data were collected using a questionnaire of developed on the basis of based on the study objectives and after a literature review of similar studies. The questionnaire used in the study was developed by including some criteria for objective assessment of asthma conditions and contained 15 questions covering monitoring, management and treatment of childhood asthma. The questionnaire was divided into two parts. The first part had questions for evaluating the overall condition of asthma and the second part contained management related questions. The questionnaires were given to patients or to their legal guardians or parents while they were present in the hospitals or clinics, after explaining the purpose of the study and obtaining verbal consent from each participant. In-door and out-door patients were included in the study. The principles of Helsinki Declaration were followed in this regard. All data were kept confidential and used only for research purposes.

Following data collection, they were entered into and analyzed by IBM SPSS Statistics for Windows, version 14 (College Station, TX: Stata Corp LP.). Pearson's chi-square or Fisher's exact test were used to analyze the difference between two study group.

\section{Results}

Table 1 summarizes the demographic and background data along with patients'/parents' perception about asthma attack. Age of majority of the patients inside Dhaka was found 6 to 16 years whereas outside Dhaka most of the patients fall in the age range of $<1$ year to 5 years. Significant variation $(p<0.001)$ was seen in case of first asthma attack time of two groups of patients. Most of the patients outside Dhaka was found to experience first asthma attack in last 12 months (79.33\%) and in Dhaka city, maximum patients first experienced it more than 5 years ago $(91.67 \%)$. In case of seasonal influence on asthma attack, none of the groups showed any variation in summer and winter seasons. However, in spring, $92.85 \%$ patients of Dhaka suffered from asthma whereas it was only $7.14 \%$ for patients outside Dhaka. Alternatively, during fall season, 71.43\% patients inside Dhaka got sick from the disease. In case of wheezing symptoms persistency, moderate $(84.62 \%)$ to severe $(78.95 \%)$ wheezing was found to be associated with the patients of Dhaka more frequently than outside Dhaka patients. Percentage of patients facing difficulty during sleep 
due to asthma was almost same for two classes of patients. Percentage of patients unable to perform activities due to asthma in two groups was also varied insignificantly. In case of background data which can affect the occurrence of asthma like use of exhaust

Table 1. Comparative situation of asthma occurrence inside and outside Dhaka

\begin{tabular}{|c|c|c|c|c|c|}
\hline \multirow{2}{*}{ Parameters } & \multicolumn{2}{|c|}{ Inside Dhaka } & \multicolumn{2}{|c|}{ Outside Dhaka } & \multirow[t]{2}{*}{$\mathrm{p}$ value } \\
\hline & Number & $\%$ & Number & $\%$ & \\
\hline \multicolumn{6}{|l|}{ Age range } \\
\hline$<1$ Year & 21 & 19.62 & 86 & 80.37 & \multirow{4}{*}{$<0.001$} \\
\hline 1-5 Year & 42 & 33.87 & 82 & 66.13 & \\
\hline 6-10 Year & 80 & 75.47 & 26 & 24.54 & \\
\hline 11-16 Year & 67 & 80.72 & 16 & 19.28 & \\
\hline \multicolumn{5}{|l|}{ First experience of asthma } & \multirow{5}{*}{$<0.001$} \\
\hline Past 12 months & 43 & 20.67 & 165 & 79.33 & \\
\hline $1-5$ years ago, & 34 & 53.12 & 30 & 46.88 & \\
\hline More than 5 years ago & 132 & 91.67 & 12 & 8.33 & \\
\hline Don't know & 1 & 25.00 & 3 & 75.00 & \\
\hline \multicolumn{5}{|l|}{ Last medication consumption } & \multirow{5}{*}{$<0.001$} \\
\hline <1 Day- 1 Year ago & 16 & 8.16 & 180 & 91.84 & \\
\hline 1 Year- <3 Years ago & 113 & 89.68 & 13 & 10.32 & \\
\hline 3 Years- 5 Years ago & 13 & 48.15 & 14 & 51.85 & \\
\hline Don't know & 68 & 95.77 & 3 & 4.23 & \\
\hline \multicolumn{5}{|l|}{ Seasonal influence } & \multirow{5}{*}{$<0.001$} \\
\hline Fall & 15 & 71.43 & 6 & 28.57 & \\
\hline Winter & 113 & 48.91 & 118 & 51.08 & \\
\hline Spring & 13 & 92.85 & 1 & 7.14 & \\
\hline Summer & 69 & 56.55 & 53 & 43.45 & \\
\hline \multicolumn{5}{|l|}{ Episodes of asthma attack } & \multirow{6}{*}{$<0.001$} \\
\hline Shorter & 85 & 60.71 & 55 & 39.29 & \\
\hline Longer & 62 & 66.67 & 31 & 33.33 & \\
\hline Same frequency & 38 & 69.09 & 17 & 30.91 & \\
\hline Recent attack was the first & 6 & 6.98 & 80 & 93.02 & \\
\hline Don't know & 19 & 41.30 & 27 & 58.70 & \\
\hline \multicolumn{5}{|c|}{$\begin{array}{l}\text { Wheezing symptoms associated } \\
\text { with asthma }\end{array}$} & \multirow{5}{*}{$<0.001$} \\
\hline Mild intermittent & 93 & 49.73 & 94 & 50.27 & \\
\hline Mild persistent & 69 & 49.64 & 70 & 50.36 & \\
\hline Moderate persistent & 33 & 84.62 & 6 & 15.38 & \\
\hline Severe persistent & 15 & 78.95 & 4 & 21.05 & \\
\hline \multicolumn{5}{|c|}{$\begin{array}{l}\text { Percentage of patients unable to } \\
\text { perform activities due to asthma }\end{array}$} & \multirow{4}{*}{$<0.005$} \\
\hline Yes & 91 & 57.23 & 68 & 42.77 & \\
\hline No & 105 & 48.84 & 110 & 51.16 & \\
\hline Don't know & 14 & 30.43 & 32 & 69.57 & \\
\hline \multicolumn{5}{|l|}{$\begin{array}{l}\text { Use exhaust fan regularly in } \\
\text { kitchen }\end{array}$} & \multirow{3}{*}{$<0.001$} \\
\hline Yes & 60 & 58.25 & 43 & 41.75 & \\
\hline No & 150 & 52.26 & 137 & 47.74 & \\
\hline \multicolumn{5}{|l|}{$\begin{array}{l}\text { Have carpeting or rugs in } \\
\text { bedroom }\end{array}$} & \multirow{3}{*}{$<0.001$} \\
\hline Yes & 44 & 33.08 & 89 & 66.92 & \\
\hline No & 166 & 57.84 & 121 & 42.16 & \\
\hline
\end{tabular}


Table 2. Management style of asthma in Dhaka and outside Dhaka

\begin{tabular}{|c|c|c|c|c|c|}
\hline \multirow[t]{2}{*}{ Parameters } & \multicolumn{2}{|c|}{ Inside Dhaka } & \multicolumn{2}{|c|}{ Outside Dhaka } & \multirow[t]{2}{*}{$\mathrm{p}$ value } \\
\hline & Number & $\%$ & Number & $\%$ & \\
\hline \multicolumn{6}{|c|}{ Percentage of patients taking medications on time } \\
\hline Yes & 174 & 60.00 & 116 & 40.00 & \multirow[t]{2}{*}{$<0.001$} \\
\hline No & 36 & 28.12 & 92 & 71.88 & \\
\hline \multicolumn{6}{|c|}{ Percentage of patients goes for routine check-up } \\
\hline Yes & 78 & 47.85 & 85 & 52.15 & \multirow{3}{*}{0.427} \\
\hline No & 118 & 52.68 & 106 & 47.32 & \\
\hline Don't know & 14 & 42.42 & 19 & 57.58 & \\
\hline \multicolumn{5}{|c|}{$\begin{array}{l}\text { Percentage of patients taking emergency treatment by } \\
\text { professionals in last } 12 \text { months }\end{array}$} & \multirow{3}{*}{$<0.001$} \\
\hline Yes & 76 & 32.90 & 155 & 67.10 & \\
\hline No & 120 & 68.57 & 55 & 31.43 & \\
\hline \multicolumn{6}{|c|}{ Used prescription inhaler } \\
\hline Yes & 111 & 68.94 & 50 & 31.06 & \multirow[t]{2}{*}{$<0.001$} \\
\hline No & 92 & 36.51 & 160 & 63.49 & \\
\hline \multicolumn{6}{|c|}{ Taken prescribed asthma medication in syrup form } \\
\hline Yes & 178 & 63.12 & 104 & 36.88 & \multirow[t]{2}{*}{$<0.001$} \\
\hline No & 32 & 23.19 & 106 & 76.81 & \\
\hline \multicolumn{6}{|c|}{ Taken prescribed asthma medication with nebulizer } \\
\hline Yes & 185 & 68.014 & 87 & 31.98 & \multirow[t]{2}{*}{$<0.001$} \\
\hline No & 25 & 16.89 & 123 & 83.1 & \\
\hline
\end{tabular}

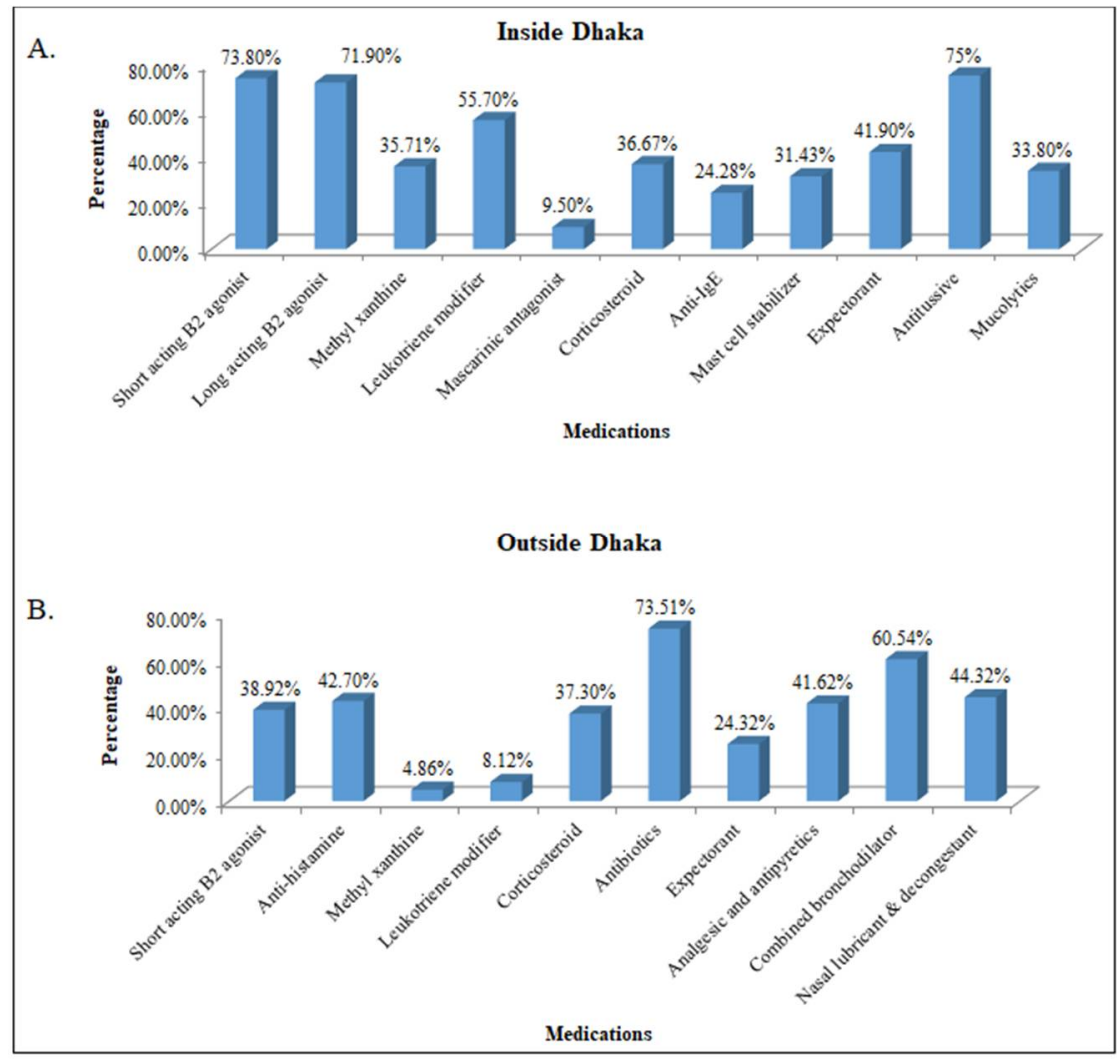

Figure 1. Medications taken by patients inside (A) and outside (B) Dhaka. 
fan regularly in kitchen, we found variation $(\mathrm{p}<0.001)$. In Dhaka, people use it more frequently (58.25\%) compared to outside Dhaka (41.75\%) dwellers. In query of presence of pets inside house which can flare up asthma attack, we didn't find any variation between the two groups $(p=0.915)$. Use of carpets inside home may serve as a source from where children might get exposed to potential allergens triggering asthma. In our study, usage of carpets was more frequent among residents of Dhaka $(\mathrm{p}<0.001)$ than residents outside Dhaka and this may be the reason of greater incidence of asthma there as compared to the other study areas outside Dhaka.

To understand management style of asthma in various locations of Bangladesh, we asked 6 questions (Table 2). Interestingly, $40 \%$ people inside Dhaka gave negative answer to the question whether they took medication on time or not as compared to $71.88 \%$ patients outside Dhaka ( $\mathrm{p}<0.001$ ). In routine checkup question, we did not find any significant variation $(p=0.427)$. Emergency treatment taking rate was very high outside Dhaka (67.12\%) compared to Dhaka city $(32.90 \%)$ having significant variations $(\mathrm{p}<0.001)$. Prescribed inhaler taking rate was high in patients of Dhaka $(68.94 \%)$ than the other group $(31.06 \%)$. Taking asthma medicines in syrup (63.12\%) and nebulized form $(68.014 \%)$ were high in patients inside Dhaka than outside Dhaka $(\mathrm{p}<0.001)$.

We observed variation in the therapeutic management of childhood asthma inside and outside Dhaka. In terms of therapeutic management of asthma, 11 different types of medicines were found to be prescribed by the physicians to both groups. Inside Dhaka (Figure 1A), we observed short-acting $\mathrm{B}_{2}$ agonists $(73.80 \%)$, long acting $\mathrm{B}_{2}$ agonists $(71.90 \%)$ and antitussive $(75 \%)$ as the mostly prescribed medications. Outside Dhaka (Figure 1B), antibiotics $(73.51 \%)$ and combined bronchodilator (60.54\%) prescription rate were pretty high. Further investigation is required to unravel the exact reason of such variation in instilling therapy against asthma and to determine whether the prescribed therapy is rational or not.

\section{Discussion}

Exploring the scenario, monitoring risk factors and treatment practice of childhood asthma would help doctors to think for modification of current asthma guidelines and treat patients more efficiently. Although bronchial asthma cause a great deal of morbidity among children in Bangladesh, epidemiological study on this issue is very low (Zaman et al., 2007). In the present study, the first part of the questionnaire contained some queries to explore overall asthma scenario. Subjects were categorized according to age in 4 groups, such as, less than 1 year, 1-5 year, 6-10 year and 11-16 year. Among these groups, less than 1 to 5 years aged patients came mostly from outside of Dhaka city and between 6 to 16 year group, majorities of the patients were from Dhaka. Reason of this variation may be multiple. In Dhaka, most of the parents are conscious about child care, conscious to maintain healthy environment for child's growth, consult to doctor at the early stage of cold problem but vice-versa picture is seen in outside Dhaka. As a result, most of these children face severe asthmatic problem. However, as they face asthma at an early stage of life, with increasing time they may develop a good immunity which may help them to fight asthma allergen at later period of life. In a study in Finland, it was seen that exposure to the farm environment in childhood, and even prenatally, decreases the risk of allergic diseases at later ages (Science Daily, 2018).

In case of seasonal influence, both winter (indoor allergen, frigid temperature) and summer (pollution, high humidity) showed same number of patient propensity, though it varied in fall and spring. People with asthma may experience worse symptoms in the fall for abundance of respiratory virus in the season. First episodes of asthma in young children in most of the cases are triggered by viral respiratory infections (AAFA, 2012). Due to presence of pollen in the air, it gets worst (American Lung Association, 2016). Interestingly, very low numbers of patients were found in these two seasons outside of Dhaka. Episodes of asthma attack (i.e., shorter/longer/same frequency) is high in Dhaka, which has been shown 
in another study (Barua et al, 2013) and in maximum case of patients outside Dhaka, recent attack was first.

Moderate $(84.62 \%)$ to severe $(78.95 \%)$ persistent wheezing was present in Dhaka city patients mostly, whereas most of the patients outside Dhaka didn't wheeze at all. Similar findings were observed in a study conducted by Control of Chronic Diseases (CCCD) of ICDDR,B (Barua et al., 2013). This means patients of Dhaka city suffer serious phase of asthma attack more frequently. Difficulty to sleep due to asthma didn't vary significantly $(\mathrm{p}=0.946)$ between patients inside and outside Dhaka. In this study, $57.23 \%$ patients inside Dhaka reported that asthma attack made them unable to perform routine activities in comparison to patients outside Dhaka, $51.16 \%$ of whom said that their performance were not affected due to asthma. The study represents that asthma patients outside Dhaka remain more active. Use of carpeting or rugs inside house was sources of huge amount of allergic asthma-causing pollutants. We found significantly $(P<0.001)$ higher percentage of children $(\sim 67 \%)$ suffering from asthma outside Dhaka had carpeting or rugs in their bedroom.

The second part of the questionnaire contained management related query. Currently there is no cure of asthma, main purpose of treatment is to control and reduce the symptoms associated with it and role of medications (BinSaeed, 2014). Significant variation $(p<0.001)$ was seen between two study population as management is better in Dhaka city. Use of prescription medicine on time, emergency treatment taking rate, inhaler/nebulizer use, taking syrup all were maintained well in Dhaka city children compared to those outside Dhaka. This may be due to low literacy, poor socio-economic structure, lack of medical facility, lack of consciousness of rural people.

While investigating the prescribed medicines in the study groups, we found that short-acting beta- 2 agonists (used for quick relief of breathing problem), leukotriene modifier (used for long term control of the disease), expectorant and mucolytic (aid in the clearance of mucus), methyl xanthine derivatives (long term control medicine) and anti-histamines are common. In Dhaka city, physicians mostly prescribe short and long acting $\mathrm{B}_{2}$ agonists, antitussive and leukotriene modifier. Outside Dhaka, antibiotics, combined bronchodilator and analgesic-antipyretic prescription rates were high. Treatment pattern was aligned with the instruction given by Asthma Association Bangladesh (Asthma Association Bangladesh, 2005) with a variation and combination with prescription of antibiotic. It was high in outside Dhaka and the reason might be that parents' demand for antibiotic. This might be due to their misconception about antibiotic and its power to help them recover quickly.

\section{Conclusion}

The present study was an attempt to evaluate the current situation prevailing in terms of occurrence and management of childhood asthma. However, this study was done in a small scale and therefore had some limitations. Firstly, in this study, we used convenient sampling, but a multi-stage stratified random sampling design would have given more precise result. Secondly, the number of populations of this study was not high enough to draw a strong conclusion about the entire population of the country. Further study including larger cohorts will give a more precise figure. Thirdly, this study used multiple questions, where recall bias could not be excluded from the answers. Nevertheless, this study demonstrates that childhood asthma and its management vary significantly in areas inside and outside Dhaka. Further detail investigation is required to get a clearer picture of childhood asthma in Bangladesh, which will help to launch appropriate interventions to decrease the rate of morbidity and mortality associated with the disease.

\section{Acknowledgements}

We would like to thank the patients and their parents/caregivers who helped us to continue the survey by giving their valuable time and information. 


\section{Disclosures}

The authors report no conflicts of interest in this work.

\section{References}

Al-Otaibi, E., and Al-Ateeq, M. 2018. Knowledge and practice of parents and guardians about childhood asthma at King Abdulaziz Medical City for National Guard, Riyadh, Saudi Arabia. Risk Manag. Healthc. Policy. 11, 67-75.

American Lung Association. 2016. Don't Fear Spring Allergies and Asthma. The article was retrieved from https://www.lung.org/about-us/blog/2016/04/dontfear-spring-allergies.

Asthma and Allergy Foundation of America New England Chapter. 2012. Asthma in Infants and Young Children. The article was retrieved from https:// asthmaandallergies.org/asthma-allergies/ asthma-ininfants-and-young-children/

Asthma-COPD-National-Guidelines. 2005. The article was retrieved from http://www.rcmc.com.bd/wpcontent/uploads/2019/01/

Barua, U.K., Saha, S.K., Ghosh, D.K. and Ruble, M.M.K. 2013. Epidemiological Study on Bronchial Asthma at Shaheed Suhrawardy Medical College Hospital, Dhaka. J. Shaheed Suhrawardy Med. Coll. 5, 77-80.
BinSaeed, A.A. 2014. Caregiver knowledge and its relationship to asthma control among children in Saudi Arabia. J. Asthma. 51, 870-875.

Cruz, Á.A., Stelmach, R. and Ponte, E.V. 2017. Asthma prevalence and severity in low-resource communities. Curr. Opin. Immunol. 17, 188-193.

Hassan, M., Kabir, A., Mahmud, A., Rahman, F., Hossain, M., Bennoor, K., Amin M.R. and Rahman, M. 2002. Self-reported asthma symptoms in children and adults of Bangladesh: Findings of the National Asthma Prevalence Study. Int. J. Epidemiol. 31, 483-488.

Kloepfer, K.M. and Gern J.E. 2010. Virus/allergen interactions and exacerbations of asthma. Immunol. Allergy Clin. North Am. 30, 553-563.

Rodrigo, G.J., Rodrigo, C. and Hall, J.G. 2009. Acute asthma in adults: a review. Chest. 125, 1081-1102.

ScienceDaily. 2018. Environmental exposures early in life modify immune responses: Effects visible even in adolescence. The article was retrieved from https://www.sciencedaily.com/releases/2018/11/18112 1142753.

The Global Asthma Report. 2018. The article was retrieved from http://www.globalasthmareport.org/

Zaman, K., Takeuch H., Yunus M., Arifeen S.E., Chowdhury H.R., Baqui A.H. and Iwata S.W.T. 2007. Asthma in rural Bangladeshi children. Indian $J$. Pediatr. 74, 539-43. 